\title{
NEW ERA IN DENTURE BASE RESINS: A REVIEW
}

\author{
Dr. Shikha Nandal ${ }^{1}$ Dr. Pankaj Ghalaut ${ }^{2}$ Dr. Himanshu Shekhawat ${ }^{3}$ Dr. Manmeet Singh Gulati ${ }^{4}$ \\ ${ }^{1}$ Senior Lecturer, Department of Prosthodontics, PGIDS Rohtak, Haryana (India) \\ ${ }^{2}$ Asst. Professor, Department of Prosthodontics, PGIDS Rohtak, Haryana (India) \\ ${ }^{3}$ Senior Lecturer, Department of Prosthodontics, PGIDS Rohtak, Haryana (India) \\ ${ }^{4}$ Dr. Manmeet Singh Gulati, MDS, Reader, Desh Bhagat Dental College \& Hospital, Muktsar, Punjab (India) \\ Corresponding Author: \\ ${ }^{1}$ Mobile: 919416512185 Email: drsnmds@ gmail.com
}

\begin{abstract}
Received :

$6^{\text {th }}$ Sept, 2013

Accepted:

$14^{\text {th }}$ Nov, 2013

Available online:

$28^{\text {th }}$ Dec, 2013

In past, the materials used for denture bases were vulcanite, celluloid \& phenol formaldehyde. Acrylic resins were introduced to dentistry in 1930's. There are certain limitations of acrylics like residual monomer allergy, poor mechanical strength, low fatigue strength, brittle on impact, poor conductors of heat, low hardness, high coefficient of thermal expansion, thermal shrinkage, poor color stability of self-cured resins, porosity, crazing, warpage, poor adhesion to metal and porcelain and requirement of mechanical retention. But still they are the most widely used denture base materials till date. But recently there has been much advancement in the field of denture base resins to overcome their drawbacks and to obtain an ideal denture base material. This article reviews the various advancements in the field of denture base resins.
\end{abstract}

Keywords: Acrylic resin, Dentures, Methacrylates

\section{INTRODUCTION}

Acrylic resins were introduced by Dr. Walter Wright and Vernon Brothers in Philadelphia. Acrylic was introduced as transparent resin in 1936 \& as acrylic powder in 1937. By 1940, 95\% Dentures made from them. Poly (methylmethacrylate) is still the most predominantly used denture base material because of its excellent esthetics, ease of processing \& repair and being economical. But it has certain drawbacks like residual monomer allergy ${ }^{1}$, poor mechanical strength, low fatigue strength, brittle on impact, poor conductors of heat, low hardness, high coefficient of thermal expansion, thermal shrinkage, poor color stability of self-cured resins, porosity, crazing, war page, poor adhesion to metal and porcelain and requirement of mechanical retention. Thus, to overcome these drawbacks, there has been much new advancement in the field of acrylics. Resins have been reinforced using different materials to improve strength. The hypoallergenic resins overcome the problems of monomer allergy. Other physical properties have also been improved by using different additives in resins. Therapeutic use of thermoplastic resins has also increased drastically in the late decade. Denture esthetics can further be improved by gum toning in the resins. ${ }^{1}$ This article reviews the various advancements in the field of acrylics.

\section{NEW ERA IN DENTURE BASE RESINS- A REVIEW}

1. Reinforced resins

a. High impact resins

b. Fiber-reinforced

2. Hypoallergenic resins

3. Resins with modified chemical structure

4. Thermoplastic resins

5. Enigma gum toning in denture bases

\section{A) REINFORCED RESINS:-}

\section{HIGH IMPACT RESINS}

Rubber reinforced (butadiene-styrene polymethyl methacrylate). Rubber particles grafted to MMA for better bond with PMMA. They are so-called because of greater impact strength \& fatigue properties, hence indicated for patients who drop their dentures repeatedly e.g. parkinsonism, senility. Available as powder-liquid system \& processing is same as heat- 
cure resins. E.g Lucitone 199 (Figure 1), D.P.I Tuff , fricke-high impact. limpact strength of D.P.I Tuff is more than Lucitone 199.

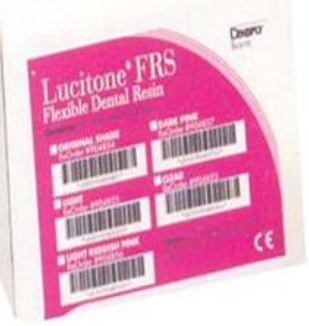

Figure 1: Lucitone 199, high impact resin

\section{FIBER REINFORCED RESINS}

Primary problem with PMMA is low impact strength $\&$ low fatigue resistance. A study by Johnston et al shows that $68 \%$ dentures fracture within few years of fabrication. Maxillary fractures are mostly caused by a combination of fatigue (under occlusal forces) \& impact (when accidentally dropped on hard surface) whereas $80 \%$ of mandibular fractures are caused by impact. Midline fractures are most common (esp. in maxilary). Fiber reinforcement result in a $1000 \%$ strength increase over non-reinforced (if there is proper bonding)

\section{a) METAL FIBER REINFORCED}

Not widely used because unesthetic, expensive, poor adhesion between wire \& acrylic resin \& metal being prone to corrosion. Using full lengths of metal fibers offers the best reinforcement. $^{2}$

\section{b) CARBON / GRAPHITE FIBER REINFORCED}

Carbon fibers $(65-70 \mathrm{~mm}$ length, $5 \%$ by weight $\&$ treated with silane coupling agent) are placed during packing. Carbon-graphite fibers are anisotropic \& provide greatest reinforcement of denture base resins in terms of flexural strength \& bending properties when placed longitudinally ( perpendicular to applied forces) but because of difficulty encountered in placing the fibres centrally fibres are placed randomly oriented. ${ }^{2}$ Carbon Graphite fibres are available as-chopped, continuous, woven, braided \& tubular but tubes of braided fibres provide a more even distribution of reinforcement, high filler loading \& easy handling because fibre bundles at different angles are advantageous when multi-axial forces are present(e.g. in implant supported prosthesis). ${ }^{3}$

\section{ADVANTAGES}

Increases flexural strength, impact strength, prevents fatigue and strengthens the resin.

\section{DISADVANTAGES}

Unesthetic because of black colour but this can be covered by an opaquer. The polishing is difficult \& also weakens the finished prosthesis. In addition, there is problem of lateral spreading of fibers during pressing.

\section{c) ARAMID FIBER REINFORCED}

Aramid fiber reinforcement increases the strength but again they are unesthetic \& difficult to polish so limited to locations where aesthetics is not important.

\section{d) POLYETHYLENE FIBER REINFORCED}

Multifibered polyethylene strands [Figure 2] cut to 65 $\mathrm{mm}$ length \& surface treated with epoxy-resin (to improve adhesion) are placed in resin during packing. They develop anisotropic properties to the composite (i.e. increase strength and stiffness in one direction).

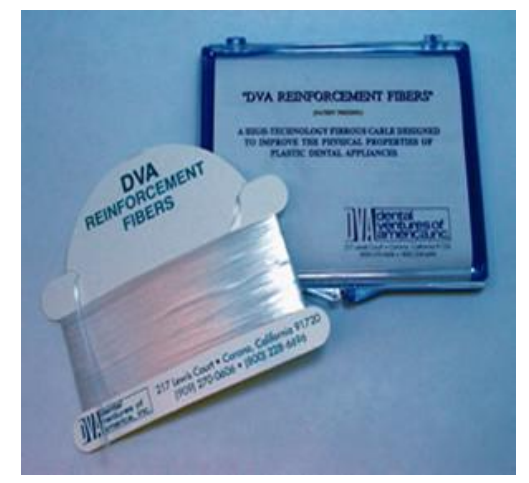

Figure 2: Polyethylene reinforcement fibers

\section{ADVANTAGES}

Exhibit highest impact strength \& modulus of elasticity but flexural properties show no significant increase. Also there is slight decrease in transverse strength but transverse strength increases if polyethylene fiber reinforcement done Triad VLC 
resin. ${ }^{4}$ Another biggest advantage is their esthetics (almost invisible).

\section{DISADVANTAGES}

Placement \& finishing is difficult as fibers tends to protrude outside mould. Moreover, polyethylene (even with plasma) does not bond.

\section{HIGHLY DRAWN LINEAR POLYETHYLENE FIBERS (HDLPF)}

Patterns of continuous parallel fibers provide maximum reinforcement to both maxillary \& mandibular bases. Reinforcement in maxilla is done by horizontally positioned fibers in anterior part of labial flange because maxillary fracture mostly occurs in midline on polished surface of palatal aspect in region immediately behind central incisors, which may be reduced by reinforcing the palate in lateral direction. Reinforcement done with 4 layers of fibers ( 2 in lateral direction sandwitched between 2 layers at 45 degree from middle ones.) by pre-preg technique (fiber content is $26 \%$ by volume). In mandible, maximum stresses appear in labial \& lingual second premolar region $\&$ fracture occurs in middle region. Thus mandibular bases are reinforced with fibers at right angle to ridge located close to polished \& fitting surface (these are regions where maximum strain occurs if flange movement takes place.). Between the two outer layers lies the main component of reinforcement i.e fibers in horizontal plane along dental arch. ${ }^{5}$

\section{ADVANTAGES}

HDLPF Have high tensile stiffness \& strength, notch insensitivity \& cracks do not propagate through array of fibers. The coherence is maintained even after a large number of testing cycles.

\section{e) GLASS FIBRES (HAVE BEST AESTHETICS)}

Continuous parallel fibers provide high strength $\&$ stiffness in one direction (anisotropic) while randomly oriented fibers provide similar properties in all directions (isotropic properties). Continuous fibers provide superior reinforcement over chopped fibres but placing continuous fibers at weak parts of denture is difficult $\&$ there is formation of voids inside fiberpolymer matrix system due to poor impregnation of fibers by resin \& polymerization shrinkage, so chopped fibers mixed with denture base acrylic resin enhance isotropic mechanical properties. Six mm chopped glass fibers with $5 \%$ fiber in combination with injection moulding technique result in increase in transverse strength, elastic modulus\& impact strength. ${ }^{6}$ Glass fibers may be modified by plasma polymerization technique using HEMA, EDA, TEGDME. $^{6}$

\section{ADVANTAGES}

These are the fibres of choice because of well documented improvement in flexural properties and fatigue resistance \& the best aesthetics \& excellent polishing characterstics. (Figure 3 ). In addition, they resist extreme temperature, moisture, oil.

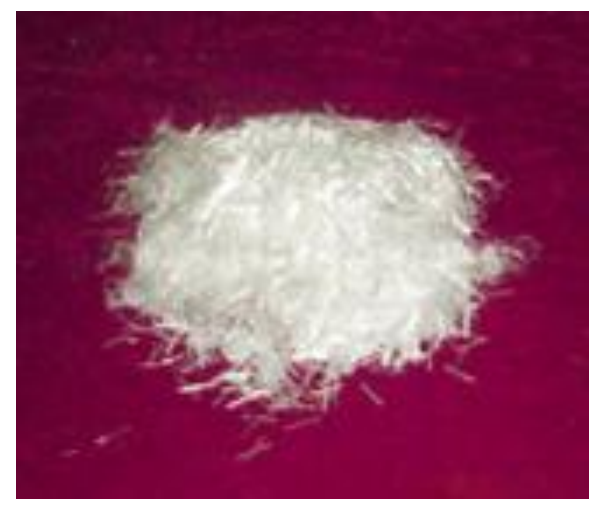

Figure 3: Glass fibers

\section{E-GLASS FIBERS}

Each strand of this E-glass is computer impregnated with a PMMA (porous polymer) and silane coupler that allows dissoloution bonding to acrylic. (e.g. Preat Perma Fiber )

\section{ADVANTAGES}

Available in two forms (mesh \& fiber) \& are transluscent providing esthetics. Because of glass fiber bonding, they also have more strength.

\section{COMPARISON OF IMPACT STRENGTH OF RESINS REINFORCED WITH}

\section{DIFFERENT FIBERS:}

Polyethylene $>$ glass $>$ thick Kevlar $>$ carbon $>$ thin Kevlar > unreinforced. ${ }^{7}$ 


\section{POSITION \& PLACEMENT OF FIBERS}

1. Place the fiber in the weakest area (On tension side during mastication) [Figure 4]

2. For repairs, place reinforcement 90 degree to the fracture. [Figure 5]

3. Unidirectional fibers are stronger, especially when direction of highest stress is known. [Figure 6]

4. Mesh should be placed on the exterior of the prosthesis, not buried. [Figure 7]

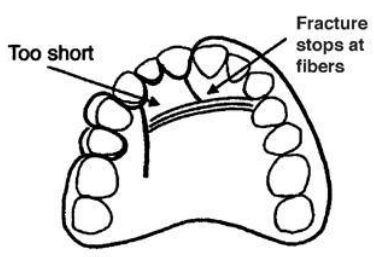

Figure 4: Fiber placed in weakest area

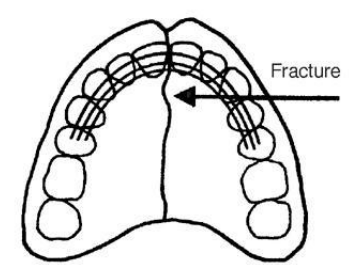

Figure 5: Fiber at $90^{\circ}$ to fracture
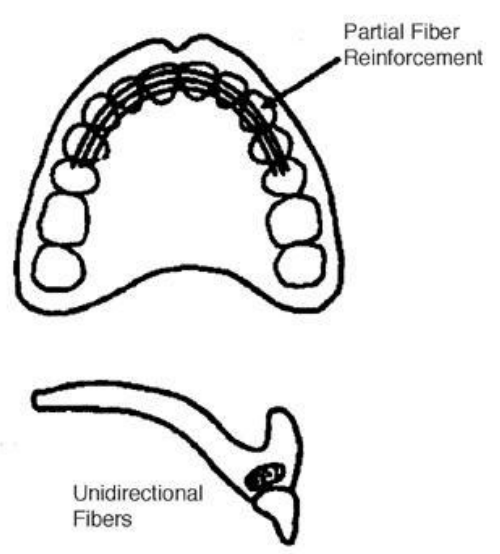

Figure 6: Unidirectional fibers are stronger
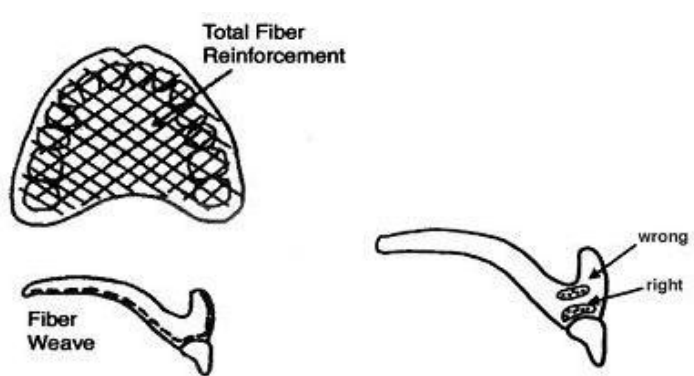

Figure 7: Mesh placed on exterior of prosthesis

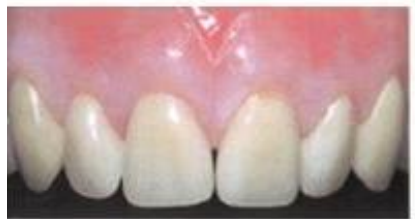

Pink Veined

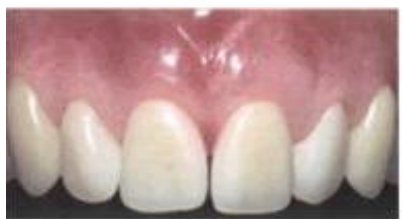

DarkBrownish Pigmentation

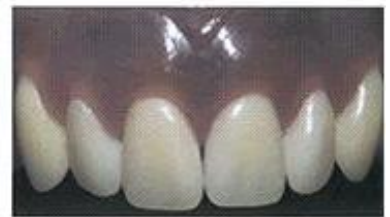

Translucent veined

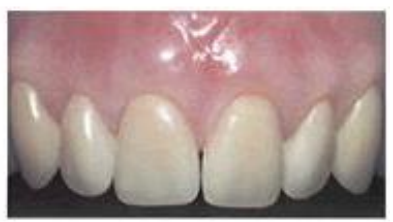

Brownish Pigmentation
Figure 8: Enigma gum toning

\section{B) HYPOALLERGENIC RESINS}

Diurethane dimethacrylate, Polyurethane, Polyethylenterephthalate and Polybutylenterephthalate. Hypoallergenic denture base materials exhibit significantly lower residual monomer content than $\mathrm{PMMA}^{8}$, thus act as alternatives to Poly Methyl Methacrylate in allergic patients. Enterephthalate based (Promysan, thermoplastic) show low water solubility than PMMA. ${ }^{9}$ Light activated indirect composite containing methane dimethacrylate (UDMA) is an alternative to PMMA for patients hypersensitive to PMMA. ${ }^{10}$ But unfortunately these materials are not completely risk free.

\section{C) RESINS WITH MODIFIED CHEMICAL STRUCTURE}

Addition of hydroxy-apatite fillers increases fracture toughness. ${ }^{11}$ Addition of $\mathrm{Al}_{2} \mathrm{O}_{3}$ fillers increases the flexural strength $\&$ thermal diffusivity that could lead to more patient satisfaction. ${ }^{12}$ The ratio of $2.2: 1$ by weight of powder to liquid was found to be the best ratio for mixing the material to give the best results in formulation. ${ }^{13} 2 \%$ quaternary ammonium compound polymerised with a denture acrylic resin displays antiseptic properties \& these dentures may be used for geriatric patients to improve their oral health. ${ }^{14}$ Addition of ceramic or sapphire whiskers to improve thermal diffusivity. ${ }^{15}$ Addition of $11-14 \%$ of several compounds of either bismuth or uranium or $35 \%$ of an organo-zirconium compound impart radiopacity equivalent to that of aluminium. ${ }^{16}$ Addition of Triphenyl Bismuth $\left(\mathrm{Ph}_{3} \mathrm{Bi}\right)$ is a promising new additive to provide radiopacity. Rawls $\mathrm{HR}$ et al found 
that cytotoxicity of PMMA was elevated slightly by inclusion of $\mathrm{Ph}_{3} \mathrm{Bi}$, probably due to decreased monomer conversion. But when stored in water, cytotoxicity was reduced, so there is high level of safety for $\mathrm{Ph}_{3} \mathrm{Bi}$ wa a radiopaque additive for denture resins. ${ }^{17}$

\section{D) THERMOPLASTIC RESINS}

This new procedure, during which a fully polymerized basic material is softened by heat (without chemical changes) and injected afterwards, has opened up a new chapter in making dentures. ${ }^{17}$

\section{ADVANTAGES OF THERMOPLASTIC MATERIALS}

Thermoplastic resins have many advantages over the conventional powder-liquid systems. They provide excellent esthetics with tooth or tissue colored materials and are very comfortable for the patient. These are very stable, resist thermal polymer unzipping, have high fatigue endurance, high creep resistance, excellent wear characteristics \& solvent resistance. They are non-porous so no growth of bacteria, and even if it is non-porous, it still retains a slight amount of moisture to keep it comfortable against gums. They are unbreakable, flexible \& light weight. Thermoplastic resins are a safe alternative to conventional resins because of very little or no monomer content. They may also be relined \& repaired by repressing the restoration. These include thermoplastic Nylon (polyamide), thermoplastic acetal, thermoplastic acrylic \& thermoplastic polycarbonate. ${ }^{17}$

\section{I.) THERMOPLASTIC NYLON}

The Basic material of thermoplastic nylon is polyamide (derived from diamine \& dibasic acid monomers). Thermoplastic nylon was introduced to dentistry in 1950's. It uses Rapid Injection System (currently known as The Flexite Company - USA) originated in 1962 which introduced the first flexite thermoplastic (a fluoropolymer - a Teflon type plastic). Thermoplastic nylon is injected at temperatures from 274 to 293 degrees Celsius. The application of nylon-like materials to the fabrication of dental appliances has been seen as an advance in dental materials. This material generally replaces the metal, and the pink acrylic denture material used to build the framework for standard removable partial dentures. ${ }^{18}$ Valplast \& flexiplast are polyamides (nylon plastics), since then there is a continued interest in thermoplastic dental materials. ${ }^{19,20}$ In 1992 , The Flexite Company, developed \& patented the first pre-formed tooth colored clasps known as Clasp-Eze, made of nylon material $\&$ is available in pink \& clear shades.

\section{ADVANTAGES}

It is virtually invisible (translucent allowing natural tissue to show through matching the basic shade categories - light pink, standard pink and meharry), and there are no metal clasps, only tissue coloured clasps that blend with natural teeth, thus provides excellent esthetics. ${ }^{20-24}$ Nylon is unbreakable, light weight $\&$ does not warp or become brittle. Because of its flexibility \& incredible patient comfort nylon is ideal for patients considering a removable partial denture, and for those allergic to monomer. In addition, it involves non-invasive procedures \& can be relined or repaired. Nylon shows no discoloration over time (colour fast) \& is non-porous so no growth of bacteria, and even if it is non-porous, it still retains a slight amount of moisture to keep it comfortable against gums. ${ }^{20-24}$

\section{LIMITATIONS}

Nylon is little more difficult to adjust \& polish. Also it is not strong enough for conventional tooth borne rest seats. ${ }^{20}$

\section{LUCITONE FRS FLEXIBLE DENTAL RESIN}

Provides aesthetic partial dentures and very strong night guards when used with success injection system (closed flask system). Advantages are same as of valplast partial resin and it has more impact resistance. 


\section{II.) THERMOPLASTIC ACETAL}

Acetal was first proposed as an unbreakable thermoplastic resin removable partial denture material in 1971. Rapid injection system developed the first tooth coloured clasps with thermoplastic fluoropolymer. ${ }^{25}$ In 1986, Dental 'D' reintroduced tooth colored clasps using Acetal resin. Acetal as a homo-polymer has good short-term mechanical properties, but as a co-polymer has better long-term stability.

\section{MECHANISM OF ACTION}

Resin clasps engage the first third (or origin) of the undercut rather than the terminal third as in metal clasps allowing three to four times the retention of metal. The clasp can then be placed more gingival increasing its aesthetic appeal beyond the obvious colored properties. $^{25}$

\section{ADAVNTAGES}

Thermoplastic acetal comes in 18 Vita shades +3 pink shades [Figure 13], to match most people's teeth or gums and clasps are tooth coloured clasps (made of acetal resin) so provide good esthetics. Labial bars can replace bulky, un-aesthetic metal swing-lock type bars. Acetal is flexible \& hypoallergenic (monomer free). The teeth and clasps can be injected together in resin, or into the existing denture adding many new applications. This can also be an aesthetic way to raise bites with a more natural feel than conventional metal openers with superior aesthetics. Adjusting is usually not necessary or recommended as the clasp is injected to the tooth contour and is permanent. There are some considerations, however, to reduce the substantial retentive properties of this type of clasp. As we do in the final fitting of the appliance on a model, one might wish to reduce the amount of retention. This is done using a black rubber point on slow speed (this material is soft). Lightly polish the guide plane. A polish kit is available for fine adjusting and polishing resin. But once the acetal resin has been trimmed away, the resin cannot be replaced; only re-injected. ${ }^{25}$

\section{LIMITATIONS}

An injected resin major connector for temporary partials is no longer recommended because the major connectors must be rigid while resin is flexible \& moreover it will not seal around the base of denture teeth allowing seepage of fluid under and around the teeth. Their use is limited in resin anterior teeth (unless they are temporary) because does not have the natural translucency \& vitality as of thermoplastic acrylic \& plyacrbonate. Also not indicated for crib Clasps in resin because unless we have a good diastema between the teeth, it won't function well. ${ }^{25}$

\section{APPLICATIONS}

Acetal resin is very strong, resists wear and fracturing, and is quite flexible. These characteristics make it an ideal material for pre-formed clasps for partial dentures, single pressed unilateral partial dentures, partial denture frameworks, provisional bridges, occlusal splints, and even implant abutments. ${ }^{26}$

\section{III.) THERMOPLASTIC ACRYLIC}

Heat-cure polymethyl methacrylate demonstrates high porosity, high water absorption, volumetric changes and residual monomer. ${ }^{27}$ Thermoplastic acrylic has poor impact resistance, but has adequate tensile and flexural strength. Thermoplastic acrylic is available in both tooth and gingival colors, and has both translucency and vitality, providing excellent esthetics. However, acrylic does not wear as well as acetal during occlusal forces and consequently will not maintain vertical dimension over long periods of time. The material is easy to adjust, handle and polish. It is relineable and repairable at the chair-side Flexite M.P.-a thermoplastic acrylic, is a special blend of polymers and has the highest impact rating of any acrylic \& does not crack even if falls on floor, thus very popular for bruxism appliances as well as dentures. ${ }^{27}$

\section{IV) THERMOPLASTIC POLYCARBONATE}

Polycarbonate is a polymer chain of bisphenol-A carbonate. Similarly to Acetal resin, polycarbonate resin is also very strong, resists fracturing, and is quite flexible. However, polycarbonate does not wear as well as Acetal during occlusal force and consequently will not maintain vertical dimension as long. Polycarbonate is not suitable for full or partial 
dentures but ideal for provisional crown \& bridges. The material has a natural translucency and finishes very well, yielding excellent esthetics. Temporary and provisional restorations with thermoplastic polycarbonate provide patients with excellent short or mid-term function and esthetics. ${ }^{25,27}$

\section{ADVANTAGES}

It doesn't use monomer and a catalyst in artisan operation process. So remaining monomer doesn't begin to melt and physical properties become stable without deteriorating. Polycarbonate exhibits little water absorption so no bad smell by saliva absorption $\&$ moreover it is safe to use i.e. no stimulation to oral mucous membrane or redness. Adherence and coherence degree is good as it has superior affinity with mucous membrane. In addition, it is superior in impact proof, stress cracking and abrasion proof. ${ }^{25,27}$

\section{DISADVANTAGES}

Elaborate processing equipment \& high moulding temperatures with greater distortion from water sorption, high flexibility, low hardness and low adhesion to acrylic teeth.

\section{APPLICATIONS OF THERMOPLASTIC RESINS}

Current dental applications of thermoplastic materials include: preformed partial denture clasp, flexible tooth born partial denture framework, single cast partial dentures, temporary crowns and bridges, provisional crowns and bridges, occlusal appliances, implant abutments, orthodontic and sleep apnea appliances. $^{28}$

\section{E) ENIGMA GUM TONING}

1) Custom shade matching of natural gingival tissue using 'Enigma' colour tones.

2) Gives extra confidence to patient in appearance of their dentures.

3) Available in Ivory, Light Pink, Natural Pink, Dark Pink \& Light Brown. Different colors are mixed to get the desired gum tone. [Figure 8]

\section{CONCLUSION}

The various advancements in denture base resins have provided promising results. Today many limitations of poly-methyl methacrylate denture base resins have been overcome. And its certain to have additional new applications in the future, to provide a better treatment $\&$ care to the patients.

\section{REFERENCES}

1. Zofia Danilewicz Stsiak. Allergy as a cause of denture sore mouth. J Prosthet Dent 1971 Jan;25(1):16-20

2. Kostoulas IE, Kavoura VT, Frangou MJ, Polyzois GL. The effect of length parameter on the repair strength of acrylic resin using fibers or metal wires. Gen Dent 2008 JanFeb;56(1):51-5

3. DeBoer J, Vermilyea SG, Brady RE. The effect of carbon fiber orientation on the fatigue resistance and bending properties of two denture resins. J Prosthet Dent 1984 Jan;51(1):119-121.

4. Susanna Segerstrom. Carbon-Graphite fiber reinforced polymers for implant superstructures. Dent Mater 2007;23:1150-1156

5. Dixon L, Breeding Larry C. The transverse strength of three denture base resins reinforced with polyethylene fibers. J Prosthet Dent 1992 March;67(3):417-419.

6. Ladizesky NH, Chow TW. Reinforcement of complete denture bases with continuous high performance polyethylene fibers. J Prosthet Dent 1992 Dec;68(6):934939.

7. Ozgul Karacaer et al. The effect of length \& concentrationof glass fibers on the mechanical properties of an injection \& a compression molded denture base polymer. J Prosthet Dent 2003 Oct;90(4):385-393.

8. Gulay Uzun, Nur Hersek, Teoman Tincer. Effect of five woven fiber reinforcements on the impact \& transverse strength of a denture base resin. J Prosthet Dent 1999 May;81(5):616-620.

9. Peter Pfeiffer et al: the residual methyl methacrylate monomer, water sorption, and water solubility of hypoallergenic denture base materials. J Prosthet Dent 2004 July;92:72-8.

10. Peter Pfeiffer, Ernst Ulrich Rosenbauer. Residual methyl methacrylate monomer, water sorption, \& water solubility of hypoallergenic denture base materials. J Prosthet Dent 2004 July;92(1):72-78

11. Tanoue N, Nagano K, Matsumara H. Use of lightpolymerized composite removable partial denture base for a patient hypersensitive to poly(methyl methacrylate), polysulfone, and polycarbonate: A clinical report. J Prosthet Dent 2005 Jan; 93 (1):17-20.

12. Mohamed SH, Arifin A, Mohd Ishak ZA, Nizam A, Samsudin AR. Mechanical \& thermal properties of hydroxyapatite filled poly (methyl methacrylate) heat processed denture base material. Med J Malaysia 2004 May;59 Suppl B:25-6

13. Ellakwa AE et al. The effect of aluminium oxide on the Flexural Strength and Thermal Diffusivity of Heat Polymerized acrylic resin. J Prosthodont 2008 August; 17(6):439-44

14. Mohamed SH, Arifin A, Mohd Ishak ZA, Nizam A, Samsudin AR. The Effect Of Powder To Liquid Ratio On Tensile Strength And Glass Transition Temperature Of Alumina Filled Poly Methyl Methacrylate (PMMA) Denture 
Base Material. Med J Malaysia. 2004 May;59 Suppl. B:1478.

15. Pesci bardon C, Fosse T, Serre D \& Medenier I. Effect Of $2 \%$ quaternary ammonium compound polymerised with a denture acrylic resin. Gerodontology. 2006 June;23(2):111116

16. PHILIP B et al. The New Acrylic Resin With Improved Thermal Diffusivity. J Prosthet Dent 1998 March;79:27884.

17. Rawls HR, Starr J, Kasten FH, Murray M, Smid J, Cabasso I. Radiopaque acrylic resins containing miscible heavymetal compounds. Dent Mater 1990 Oct;6(4):250-5.

18. Rawls HR, Marshall MV, Cardenas HL, Bhagat HR, Cabasso I.Cytotoxicity evaluation of a new radiopaque resin additive - triphenyl bismuth. Dent Mater 1992;8(1):54-9.

19. Negruțiu M, Sinescu C, Sandu Liliana, et al. Guidelines of removable partial dentures, Ed. Marineasa, Timişoara, 2004.

20. Lowe LG. Flexible denture flanges for patients exhibiting undercut tuberosities and reduced width of the buccal vestibule: a clinical report. J Prosthet Dent 2004;92(2):12831.

21. Phoenix RD, Mansueto MA, Ackerman NA, et al. Evaluation of mechanical and thermal properties of commonly used denture base resins. J Prosthodont 2004;13(1):17-27.
22. Janda R. Prothesenkunststoffe aus werkstoffkundlicher Sicht. Quintessenz Zahntech 1997;23(5):665-72.

23. Negruțiu M, Romînu $M$, Florița $Z$, et al. Influența tehnologiei de prelucrare asupra calității polimerilor pentru proteze mobile şi mobilizabile. Revista de Stomatologie 2001;V(1/2):107-12.

24. Parvizi A, Lindquist T, Schneider R, et al. Comparison of the dimensional accuracy of injection-molded denture base materials to that of conventional pressure-pack acrylic resin. J Prosthodont 2004;13(2):83-9.

25. Keenan PL, Radford DR, Clark RK. Dimensional change in complete dentures fabricated by injection molding and microwave processing. J Prosthet Dent 2003;89(1):37-44.

26. Donovan TE, Cho GC. Esthetic considerations with removable partial dentures. J Calif Dent Assoc 2003;31(7):551-7.

27. Meda Negrutiu, Cosmin Sinescu, Mihai Romanu, Daniela Pop, Sorin Lakatos. Thermoplastic Resins for Flexible Framework Removable Partial Dentures. TMJ 2005; 55(3);295-99

28. Janda R. Prothesenkunststoffe aus werkstoffkundlicher Sicht. Quintessenz Zahntech 1997;23(5):665-72. 